\title{
CALAS EN LA SEMÁNTICA Y LA SINTAXIS DEL ESPAÑOL ACTUAL
}

\section{Por: Alvaro William Santiago G. Jose Ignacio Correa M.*}

\section{ASPECTOS PREVIOS.}

Las negociaciones comunicativas que, como seres sociales, entablamos en nuestro diario quehacer, nos proveen del material suficiente para adelantar los análisis que requiere la asignatura de Sintaxis Española, en el aula de clase. Lamentablemente, no se puede afimar lo mismo en lo que a la producción bibliográfica se refiere. Pareciera como si las actuales corrientes de estudio del lenguaje sólo mostraran una preocupación mínima por el código verbal castellano, en especial, por el que se usa aquende la península ibérica. Asimismo, es de suponer que la persistencia investigativa de los lingüistas se mantiene en ascenso, pero que su producción no nos llega por diferentes motivos: ora porque nuestras bibliotecas están desactualizadas, ora porque el mercado del libro no manifiesta gran predilección por las nuevas producciones de la lingüística teórica o aplicada, ora porque es reducido el radio geográfico que logran las publicaciones de tales investigadores.

En las condiciones expuestas, nuestro quehacer docente aboga por la existencia de formulaciones teóricas que, recogiendo los aportes de connotados lingüistas y confrontándolos con otros acercamientos conceptuales, proporcionen información actualizada con respecto a las diversidades que, en el uso del código lingüís tico, muestran los hispanoparlantes.

\section{ACERCA DE LAGRAMÁTICA ESPAÑOLA}

Indudablemente, los estudios gramaticales han avanzado tanto como la misma ciencia del lenguaje, sin embargo, es -asimismo- indudable que la mayoría de investigaciones y de propuestas analíticas se han dedicado a dar cuenta de la exterioridad formal del código lingüís tico. Y este hecho se hace mucho más notorio si nos detenemos a observar los aspectos relacionados con nues tra propia lengua.

Nadie pone en duda que, con escasas y notables excepciones, los estudios de gramática castellana han buscado exponer las pautas de comportamiento lingüístico a que tienen que responder los usuarios (idealizados, eso sí), ya sea en España a o en América o, incluso, en una y otra indistintamente. Es decir, se han realizado exposiciones que favorecen el conocimiento de una noma (la sistémica) que se encuentra alejada de la que surge del uso cotidiano en situaciones comunicativas específicas, entabladas por interagentes de carne y

\footnotetext{
* Profesores Universidad Pedagógica Nacional.
} 
hueso, con intenciones y cargas culturales e ideológicas que los definen y particularizan.

La Gramática... de Nebrija, precursora de cuantas se han publicado hasta hoy, se encuentra dividida en cinco partes o libros, a saber: 1. Partes de la gramática y Ortografía; 2. Prosodia y sílaba; 3. Etimología; 4. Sintaxis y estilística; y 5. Instrucciones para los extranjeros que quieren aprender el castellano; y, aunque sus sucesoras han intentado alejarse del modelo, todavía se mantienen criterios emparentados con los del autor andaluz, especialmente en lo que se refiere a asumir que «para que pueda perdurar una lengua es preciso regularla mediante la gramática» e, incluso, concepciones emparentadas con aquello de que la lengua ha sido (y posiblemente continúa siendo) «compañera del imperio».

Dado que la teoría lingüística (desde sus inicios, de inspiración positivista, hasta los actuales trabajos, de orientación fenomenológica, multidisciplinarios y nada empiristas) posee suficientes elementos de juicio para adelantar una relectura del quehacer gramatical, hemos considerado que se hace necesario proponer un acercamiento diferente al problema, en especial asumiendo los aportes de la pragmática, la etnografía de la comunicación y la semiótica. En otras palabras, la tarea fundamental de los lingüistas contemporáneos debe encaminarlos hacia la elaboración de una gramática que también dé cuenta del uso y no sólo que lo prefigure.

Con el ánimo de propiciar el desbroce del camino entre nuestros estudiantes, a continuación expondremos algunos de los aspectos que se hallan en concordancia con la constitución del sentido del enunciado, por parte de actualizadores como la Modalidad y el Auxiliar. Para el efecto, se tendrán presentes muchos de los presupuestos teóricos de la gramática conceptual o de casos, de la pragmalingüística, de la filosofía y de la semiótica, por cuanto es apenas natural que cualquier contexto situacional (el cual exige de los interagentes del proceso comunicativo unas competencias de carácter lingüístico, pragmático, tímico, cultural e ideológico) sólo puede ser explicado mediante el esfuerzo mancomunado de las disciplinas que tienen algún interés al respecto.

\section{LA REVISIÓN DE LOS ENFOQUES.}

Para efectos de las líneas que a continuación se esbozan, y como hipótesis de trabajo, entendamos por lenguaje aquella capacidad exclusiva del ser humano que le proporciona las herramientas suficientes para apropiarse conceptualmente de la realidad (empírica o no), para relacionar los resultados de esa apropiación con miras a la conformación de corpus de ideas y para, finalmente, pemitirle la generación de sistemas sígnicos encaminados a satisfacer su necesidad de referir intencionalmente el universo del que se ha apropiado. Es de aclarar que, aunque algunos sistemas no siempre hacen po- 
sible la expresión de mensajes, sí conllevan similar potencialidad semiótica, no obstante la inobjetable supremacía semántica que el código lingüístico mantiene sobre todos los demás, en tanto hace uso de sus caracterís ticas de as equibilidad a todos los usuarios y de su interpretancia del mundo y de los otros códigos.

Debido a la mencionada supremacía, la lingüística se ha dedicado -casi exclusivamente- al estudio de la lengua y no al del lenguaje, como es apenas lógico que lo hiciera.

Y es por ello que, en casi todos los casos se han dejado de lado aquellos aspectos que no pueden ser formalizados des de la perspectiva del código verbal, y el accionar de la lingüís tica ha sido -fundamentalmente- de carácter gramatical y, en no pocas ocasiones, nomativo y dogmático.

Por el contrario, el modelo de gramática por el que propugnamos, va encaminado a acercar a los usuarios a la explicación de su manera de asumir el código en una interacción comunicativa y unas condiciones espacio-temporales, anímicas e ideológicas determinadas. Por lo tanto, está obligado a dar cuenta de las estructuras conceptual, formal y evidente de cualquier actuación lingüística. Sólo así, la gramática dejará de centrar su atención en el nivel formal-abs tracto del sistema, la oración, y podrá dar cuenta del hecho real comunicativo, el enunciado, y, a través suyo, del discurso. En otras palabras, la gramática que se plantea tendrá que ocuparse no tanto del significado que subyace a la emisión verbal, como del sentido que ésta encierra.

\section{HACIA LA ESTRUCTURA CONCEPTUAL}

Si partimos de asumir que el concepto es la resultante de relacionar las diferentes abstracciones que el ser humano ha ido transformando en ideas ${ }^{1}$, es necesario que encontremos -en la base de la palabra que refiere un objetoaquella esencia de que nos habla Boguslavski y aquellas «relaciones de la realidad objetiva, [las cuales constituyen] un reflejo de sus vínculos internos, de lo general que tiene existencia objetiva y que los une» ${ }^{2}$, o dicho de otra manera, es necesario que reconozcamos la existencia de un sistema de conexiones semánticas que funciona como sustento -en el nivel del pensamiento- de la palabra con que entablamos nuestras cotidianas negociaciones comunicativas.

Pero, también, es imprescindible que concibamos esa red de ideas interconectadas como una entidad en pemanente evolución, predispuesta para servir

\footnotetext{
${ }^{1}$ Al respecto, cf r. A. s. Ajmánov, Las formas lógicas y su expresión en el lenguaje; y. M. Boguslavski,

La palabra y el concepto; O. P. Gorski, Lenguaje y conocimiento; en: Pensamiento y lenguaje; A. R. Liria, Lenguaje y pensamiento; L. S. Vygotski, Pensamiento y lenguaje, entre otros.

${ }^{2}$ V. M. Boguslavski, op. cit., pág. 192.
} 
a la codificación y la decodificación (es decir: a la comunicación), y equipada para proponer tentativas de solución a los problemas relacionados con el pensamiento.

Pues bien, a esa red de ideas interconectadas que sustentan un pensamiento completo y que resumen un problema de conocimiento, la denominamos proposición.

La proposición, de acuerdo con la manera como problematice el mundo, narrándolo o des cribiéndolo, puede ser -en su orden- fenoménica o atributiva; pero siempre tendrá un elemento predicador [un verbo (fenoménica) o un no-verbo (atributiva)], referido a "una o varias entidades, cada una de las cuales está relacionada con aquél según una de las funciones semánticas conocidas como casos».

\section{HACIA LA ESTRUCTURA}

En la estructura sintáctica encontramos la oración como elemento primordial para adelantar su estudio. Se entiende la oración no como unidad de habla sino como entidad abstracta y formal que, para la asignación de las funciones que desempeñan sus componentes, toma como punto de partida las categorías lógicosemánticas (agente, objeto, beneficiario, instrumento, locativos espacial y tem poral), los cuales pueden des empeñar la función de sujeto o de complemento, de acuerdo con la intención comunicativa que anima a los interagentes.

Chafe plantea que existen múltiples mecanismos postsemánticos mediante los cuales una estructura semántica o conceptual se transforma en una sintáctica y que «parece que tales procesos tienen su origen en tres áreas distintas. En primer lugar, está la necesidad de que las estructuras semánticas no lineales se conviertan en figuraciones lineales apropiadas para convertirse posteriomente en sonido $[\ldots]^{4}$.

Entre los procesos postsemánticos que determinan el paso de la estructura conceptual a la oracional, tenemos: la linearización (a partir de una estructura preposicional, jerárquica se llega a una estructura linear o bosquejo com unicativo); la elección del sujeto (es decir: cuál actante del nivel semántico cumplirá la función gramatical del sujeto); la elección del tema (o información compartida); y la elección del foco (o elemento portador de la fuerza ilocucionaria).

\section{HACIA UNA ESTRUCTURA PRAGMÁTICA}

\footnotetext{
${ }^{3}$ Charles Filmare, Algunos aspectos de la gramática de casos, en: Semántica y sintaxis en la lingüística transformatoria, Alianza Editorial, Madrid, 1976. Conviene, también, revisar el capítulo "Categorías de relación evenimencial y existencial", apud Hacia una base semántico-comunicativa para la gramática, de Tito Nelson Oviedo. Universidad del Valle, Cali, 1992.

${ }^{4}$ Wallace L. Chafe. Apud, Significado y estructura de la lengua. Editorial Planeta, Barcelona, 1976. Pág. 67.
} 
Charles Fillmore considera que la oración está conformada por la Modalidad, el Auxiliar, la Frase Nominal y la Frase Verbal ${ }^{5}$. Sin embargo, teniendo en cuenta que las dos últimas constituyen la reescritura formal de la Proposición y los primeros aportan elementos que contextualizan la emisión verbal, nosotros preferimos hablar de la Modalidad (por lo menos de la denominada epistémica) y del Auxiliar en relación con el enunciado y, por lo tanto, con el discurso.

Partiendo de la evidencia que tenemos de que el enunciado no se estructura formal sino pragmáticamente, estamos obligados a reconocer el papel transformador de los elementos que propician la constitución de sentido dentro del producto lingüístico. Tales elementos son, entre otros, los anafóricos, el artículo, la modalidad y el auxiliar. Analicemos, con un poco más de detalle, los dos últimos.

\subsection{LA MODALIDAD}

Los teóricos que se han detenido en el concepto de modalidad han ubicado su radio de acción en disciplinas como la sintaxis, la semántica y la filosofía, entre otras. No obstante, nosotros consideramos de capital importancia abordar su estudio de acuerdo con la estructura en la cual tiene incidencia, por cuanto muy diferente será el papel que desempeñe.

5.1.1. Denominamos MODALIDAD LÓGICO-AMBIENTAL a aquélla que ejerciendo su influencia sobre el nivel proposicional- ayuda a la conformación del escenario en el cual desempeñarán sus roles los actantes, una vez entren en relación con la acción, el proceso o la acción-proceso, o acción compleja, como la denomina Ricoeur'. Ese escenario alcanza dimensiones espaciales, temporales, causales, finales, etc., y se constituye en la demarcación contextual que circunscribe a la proposición misma.

5.1.2. La MODALIDAD DE LA ACCIÓN VERBAL, ubicada en el nivel oracional, se identifica con los cieno- mi nados verbos modales (aquel las unidades léxicas que han perdido su carga semántica primigenia $y$, a cambio, adoptan un significado gramatical,

deteminado por el sistema lingüístico en el que se encuentren inmersos), los cuales ofrecen matices peculiares al significado del predicador (Vid. 5.2.3.).

5.1.3. La que aquí se denomina -a falta de un nombre mejor- MODALIDAD EPISTÉMICA, la cual desde nuestra perspectiva, se diferencia significativamente de la homónima que Lyons definió en relación con los criterios de verdad y de falsedad, propios de la lógica proposicional'7.

\footnotetext{
${ }^{5}$ Cfr. lo expuesto por Ch. Fillmore en Una teoría moderna de los casos, en: Los fundamentos de la gramática transformacional, Siglo XXI Editores, México, 1974. Págs. 50 ss.

${ }_{7}$ Paul Ricoeur, El discurso de la acción, Ediciones Cátedra, Madrid, 1981. Págs. 11 ss.

7 John Lyons, Semántica, Editorial Teide, Barcelona 1980. Págs. 725-741. 
La modalidad epistémica por la que aquí se propugna, está relacionada tanto con el conocimiento del locutor y del interlocutor sobre el mundo que refieren e interpretan (y sus consecuentes condiciones de verdad, veracidad y rectitud), como son:

La actitud que adopta el locutor frente a lo dicho y frente a la relación que establece con su interlocutor. Se podrá, entonces, dar cuenta de la fuerza ilocucionaria que permite asumir un enunciado como pregunta, afimación, mandato, etc.

- La intención del locutor al referir determinados aspectos y no otros y sus connotaciones ideológicas. Este aspecto permitirá explicar la remisión del interlocutor a una determinada jerarquización y a una relación con el poder establecido por el discurso mediador.

- La conceptualización que se ha hecho del mundo que se refiere y que se interpreta. En otras palabras, este factor da luces para entender el sustento cultural que contextualiza a locutor e interlocutor.

- La intención que anima al interlocutor al adelantar detem inada(s) lectura(s) y no otra(s) del discurso iniciado por el locutor. Este as pecto nos permite ofrecer explicación a la instauración de las lecturas aberrantes a que hace alusión Umberto Eco ${ }^{8}$ " cuando menciona aquellas decodificaciones que propician una interpretación no prevista por el locutor y que, en no pocas ocasiones, pueden estar en oposición con la intencionalidad que lo llevó a producir su enunciación.

\subsection{EL AUXILIAR}

Es otro de los actualizadores que se emplea para la proyección de mensajes -no necesariamente explícitos-por parte del locutor, los cuales sí van a ser recogidos por el interlocutor -aunque no siempre en forma consciente-. Para efectos de la constitución del sentido, las informaciones pueden organizarse en tres grandes grupos: las correspondientes al Tiempo, el As pecto y el Modal.

5.2.1. El tiempo ha sido analizado desde perspectivas diferentes, a tal punto que se ha hablado -y se habla aún- del tiempo psicológico, del tiem po cronológico, del tiempo gramatical, del tiempo vivencial, como categorías que de hecho son diferenciables ${ }^{9}$.

\footnotetext{
${ }^{8}$ Cfr. "El problema de la recepción", en: Sociología contra psicoanálisis, Ediciones Martínez Roca Barcelona, 1974. Págs. 13-20. Cfr., asimismo, Lector in fábula, Editorial Lumen, Barcelona, 1987 Págs. 85-87.

${ }^{9}$ No olvidemos, induso, la propuesta de Heidegger, cuando caracteriza "un 'estado de abierto, propio del "ser ahí" y le asigna una temporalidad del comprender, del encontrarse y del hablar, la cual les proporciona plena articulación, aunque la "temporación" no signifique una secuencialidad,
} 
Partamos, para cumplir con nuestro cometido, de la propuesta kantiana de considerar al tiempo como 'a priori', es decir, como algo independiente de la experiencia en la medida en que cualquier percepción sensible es una vivencia, algo que le acontece al Yo. En esa dirección, todo acontecer es un devenir, un llegar a ser lo que no se es todavía, quizá como contraposición a la afirmación de Spinoza acerca de que «todas las cosas se esfuerzan, cuanto está a su alcance, por perseverar en su ser». Y es aquella concepción metafísica del tiempo (no necesariamente originaria -aunque sí modernizada- por Kant) la que ha pemitido entender por qué razón la palabra puede, como la aritmética, plantear un suceso detrás de otro.

Sin embargo, los usuarios transgreden continuamente la norma sistémica imperante $y$, los tiempos gramaticales, no han sido la excepción. Ellos se estremecen y desplazan sin miramientos, de una a otra posibilidad de significación.

El locutor usa la temporalidad presente para establecer su visión de un pasado que no puede evocar, por no vivido:

En la conquista de América hay hombres como Cortés, los Pizarro...

(GERMAN ARCINIECAS)

O puede, asimismo, volcarse hacia la exposición de un futuro que no se puede más que suponer, por lo tanto tan irreal como ese pasado que nunca se vivió:

Con es tos ojos no me muero. (G. García Márquez), En media hora estamos en esa ciudad.

El pasado, por su parte, puede posibilitar la existencia de un fenómeno lingüístico particular: que se indique hacia el futuro y que, al mismo tiempo, se dé cuenta de un pasado en el cual tuvo lugar la enunciación del mensaje que refiere otro futuro:

Hoy hablaba el presidente por televisión.

El profesor Gutiérrez Girardot venía en diciembre.

En ambos casos, el pretérito imperfecto proporciona enunciados subyacentes del tipo:

(Nos enteramos de que] hoy hablaba el presidente. [Leí que] el profesor Gutiérrez G irardot... 
Los enunciados transcritos nos permiten entrever que el locutor posee un conocimiento que no ha sido aprehendido directamente, sino que lo expuesto proviene de otro discurso, es decir: esos enunciados constituyen una foma particular de la citación o polifonía ${ }^{10}$

Si asumimos un concepto de citación que incluya la evocación como réplica mas o menos fiel de un enunciado anterior, es decir, la verbalización que incita al interlocutor a encontrar el modelo en que se basa la réplica; o si consideramos que el discurso tiene posibilidad de hacerse concreto, tenemos que aceptar que efectivamente el pretérito imperfecto se constituye en apertura hacia el territorio de la polifonía, por cuanto

desde un plinto de vista pragmático. no veo diferencias en el mecanismo: por medio de los verbos y de otras fomas lingüísticas, los hablantes evocan, es decir, citan, tanto segmentos recientemente producidos cuanto otros mas remotos, y tanto segmentos efectivamente producidos (Ilanto) segmentos presupuestos $^{11}$.

Así, pues, un enunciado que se aglutina alrededor de un verbal que utiliza la convención del pretérito imperfecto, puede ser transmisor de otro, producido con antelación; pero también puede ser portador de enunciados presupuestos. En la secuencia: Hoy hablaba el presidente..., existen presuposiciones del tipo de: el AGENTE es portador de los semas [+animado], [+ humano], [+ masculino], [+ elegido democráticamente], [+capacitado para hablar], el VERBAL indica que [+pasado] el agente iba a hablar pero no lo hizo; el VERBAL indica que [+ pasado] el locutor no tiene la certeza de si el agente habló o no; el VERBAL indica que [+ futuro] aún no ha hablado pero hablará...

Trátese, entonces, de un enunciado virtual o actualizado, no por ello el pretérito imperfecto pierde sus potencialidades citativas, máxime si asumimos que «presuponer una oración es abrir automáticamente un espacio intertextual» ${ }^{12}$

Es de anotar que la caracterización tradicional del modo, es decir del compromiso que adopta el locutor con respecto a la acción que narra, la incluimos en este apartado, por cuanto esta complementando la información acerca de la incidencia temporal, informando acerca de la asunción de un compromiso (modo indicativo); ningún compromiso con la verdad que sus tenta la proposición (modo subjuntivo); o inexis tencia de opción veritativa con la cual comprometerse (modo imperativo).

5.2.2. El aspecto que analizaremos aquí será, exclusivamente, el que se constituye en modalizador del enunciado, es decir: el aspecto gramatical. Para nada

\footnotetext{
${ }^{10}$ Cfr. Oswald Ducrot, Polifonía y argumentación, Universidad del Valle, Cali, 1988. Págs. 15-29.

${ }^{11}$ Graciela Reyes, Tiempo, modo, aspecto e intertextualidad, en: Revista española de lingüística, enerojunio de 1990. No. 20, fascículo 1, pág. 20.

12 Ibídem, pág. 21.
} 
tomaremos el aspecto léxico, es decir, aquél que está dado por la significación del verbo mismo.

Tradicionalmente hemos asumido que el as pecto gramatical se encamina a dar información acerca del punto de vista del locutor con respecto al comienzo, desarrollo o culminación del evento: si la flexión indica que el evento ha culminado, estaremos frente al aspecto perfectivo; si da cuenta de una acción en desarrollo, frente al as pecto durativo y, si el evento inicia o no ha concluido, frente al aspecto imperfectivo.

No obstante, es necesario recordar que, cuando se trata de perífrasis verbales o de enunciados negativos, podemos encontrar que -en el nivel semántico- la normatividad también puede ser transgredida. Un enunciado del tipo de

No vino

se constituye en imperfectivo -por no realizado- aunque, gramaticalmente, se tenga que hablar de perfectividad. Mientras que otro, del tipo de

Debieron de sonar seis campanadas

se toma imperfectivo gracias al cariz de potencialidad que le proporciona a la acción el verbo modal.

5.2.3. Y llegamos al último constituyente del auxiliar: el que aquí denominamos MODAL, caracterizado por la opción que tiene el locutor de matizar con sentidos su enunciado a partir de la actividad transfomacional ejercida en línea directa sobre la acción verbal, hecho éste que es posible gracias a la inclusión de entidades léxicas que, como ya dijimos, han perdido su carácter semántico original y han adoptado -merced a un régimen particular-otro muy diferente. Este parágrafo busca, de alguna manera, responder a lo planteado por Oviedo, en 1992, cuando afima que

Queda faltando un análisis más detallado de la categoría del Auxiliar Modal, o sea, del proceso de modalización [...] lgualmente, falta precisar qué elementos son necesarios para definir la categoría de Modal. (Op. Cit., pág. 176)

En español reconocemos ocho categorías de verbos modales, a saber

(Ver tabla siguiente)

Del uso de uno u otro verbo modal pueden surgir perífrasis que -si bien, gramaticalmente, tienden a dar idea de un aspecto perfectivo- poseen una proyección semántica que puede no serlo. (Vid.5.2.2.) 
También, es posible que el uso de la perífrasis genere interacciones comunicativas con menos carga de violencia, aunque la intención se mantenga. Los enunciados:

Tienen que hacer los ejercicios

Deben hacer los ejercicios

Hay que hacer los ejercicios

plantean diferentes grados, en orden descendente, de la obligatoriedad que implica el uso del modal. Sin embargo, es apenas obvio que no por ello dejarán de ser enunciados a los que subyace una gran carga perlocutiva.

VERBOS MODALES DEL ESPAÑOL ${ }^{13}$

\begin{tabular}{|c|c|}
\hline MODALIZACIÓN & LOS MODALES Y SU RÉGIMEN GRAMATICAL \\
\hline \begin{tabular}{|l|} 
Incoativa \\
\end{tabular} & $\begin{array}{l}\text { Ir a, pasar a, echar a, romper a, comenzar a, empezar a, } \\
\text { principiar a, SEGUIDOS POR EL VERBO PRINCIPAL EN } \\
\text { INFINITIVO. }\end{array}$ \\
\hline \begin{tabular}{|l} 
Aproximativa \\
\end{tabular} & $\begin{array}{l}\text { En lo temporal: (Des de el ahora) ir; (en el ahora) seguir; (hacia } \\
\text { el ahora) venir, CON EL VERBO PRINCIPAL EN } \\
\text { GERUNDIO. } \\
\text { En lo conceptual: (Centrífuga) salir, + VERBO PRINCIPAL EN } \\
\text { GERUNDIO; (Centrípeta) venir a, seguir a CON } \\
\text { VERBOPRINCIPAL EN INFINITIVO. }\end{array}$ \\
\hline Obligativa & $\begin{array}{l}\text { Haber de, haber que, tener que, y deber, SEGUIDOS DE } \\
\text { INFINITIVO. }\end{array}$ \\
\hline Durativa & Estar SEGUIDO DE GERUNDIO. Hipotético-potencial \\
\hline $\begin{array}{l}\text { Hipotético- } \\
\text { potencial }\end{array}$ & Deber de y poder, SEGUIDOS DE INFINITIVO. \\
\hline Volitiva & Querer, SEGUIDO DE INFINITIVO. \\
\hline \begin{tabular}{|l} 
Iterativa \\
\end{tabular} & $\begin{array}{l}\text { Andar y quedar, SEGUIDOS DE GERUNDIO; y volver a, } \\
\text { SEGUIDO DE INFINITIVO. }\end{array}$ \\
\hline Terminativa & $\begin{array}{l}\text { Acabar de, alcanzar a, terminar de, SEGUIDOS DE } \\
\text { INFINITIVO; y llevar, tener, traer y quedar, SEGUIDOS } \\
\text { DEPARTICIPIO. }\end{array}$ \\
\hline
\end{tabular}

${ }^{13}$ Como referencia se han tomado, entre otros, los estudios de Lenz: La oración y sus partes; Gili Gaya: Curso superior de sintaxis española; Roca Pons: Estudios sobre perífrasis verbales del español; R. Seco: Manual de gramática española; T. N. Oviedo: Hacia una base semánticocomunicativa para la gramática. 


\section{EL PROBLEMA CONTINÚA VIGENTE}

Los planteamientos que has ta aquíse han hecho, nos pemiten entrever que una gramática de lengua española que pretenda dar cuenta, no sólo de la normatividad existente, sino -incluso en contravía suya- que explique las necesidades y las opciones de transgresión que el sistema proporciona, tiene que nutrirse con los aportes que puedan ofrecerle otras disciplinas. Es posible que, entonces sí, la lingüística (o alguna entidad de carácter multidisciplinario) pueda dar solución a problemáticas como:

La necesidad de explicar (y no de prefigurar mediante la noma y el dogma) lo que muestra el uso lingüístico. Entrever los mecanismos a través de los cuales los hablantes hacen uso del verbo modal con intenciones connotativas que se constituyen en modalizadoras de la acción verbal.

Reconocer las estrategias discursivas que convierten al verbo modal en un ama de generar sentidos, la cual actúa como modalizadora del aspecto.

Explicar cabalmente la negación y las razones por las cuales influye sobre el aspecto -y al mismo tiempo-se constituye en una manifestación la intertextualidad.

Por ahora, con ánimo divulgativo, sólo se han expuesto algunas de las calas que hemos podido hacer a factores determinantes del uso, como son la modalidad, el tiempo, el aspecto, el verbo modal y la citación a través de un tiempo gramatical específico: el pretérito imperfecto. Esperamos ofrecer, posteriomente, otras reflexiones al respecto, en la medida en que -como la evolución de la lengua misma- las perspectivas de análisis se cualifican, a la vez que nos proveen herramientas mucho más aptas para dar cuenta de nuestro objeto: la lengua española. 